\title{
Asi Nehrinin su kalite parametre düzeylerinin belirlenmesi
}

\author{
Determination of water quality parameters of Asi River
}

\author{
Necat AĞCA ${ }^{1 \mathcal{O}}$ (D), Kemal DOĞAN ${ }^{1}$ iD \\ ${ }^{1}$ Hatay Mustafa Kemal University, Faculty of Agriculture, Department of Soil Science, Antakya-Hatay, Turkey.
}

MAKALE BILGISI / ARTICLE INFO

Makale tarihçesi / Article history:

DOI: $10.37908 /$ mkutbd.585057

Geliş tarihi /Received:01.07.2019

Kabul tarihi/Accepted:02.01.2020

\section{Keywords:}

Asi River, Water quality, physico-chemical properties.

\footnotetext{
Corresponding author: N. AĞCA

$\bowtie$ : necagca@gmail.com
}

\author{
ÖZET / A BSTRACT
}

Atıf / Citation: Ağca N, Doğan K (2020) Asi Nehrinin su kalite parametre düzeylerinin belirlenmesi. MKU. Tar. Bil. Derg. 25(1) : 1-9. DOI: $10.37908 / \mathrm{mkutbd} .585057$

\section{Giriş}

İnsanların gereksinimleri arttıkça temiz suya olan gereksinimleri de artmaktadır. Temiz su; içme, tarım ve endüstriyel amaçlı kullanılmaktadır. Nehirler, tropik ve suptropik bölgelerde en önemli içme suyu kaynaklarıdır. Fakat son 50 yıldır özellikle antropojenik nedenlerle dünyanın birçok nehrinin su kalitesinde önemli düşmeler olmuştur (Padmalal ve ark., 2012).

Bir nehirdeki suyun kalitesi; hem doğal, hem de antropojenik kaynaklardan önemli ölçüde etkilenmektedir. Arazi kullanım şekli, toprak erozyonu, tarımsal kimyasalların kullanımı, çeşitli atıkların atılması gibi faaliyetler en önemli insan aktiviteleridir. Su kalitesinin değerlendirilmesi ve yönetimi, su karakteristiklerindeki yersel ve zamansal değişimi anlamayı gerektirir (Phung ve ark. 2015). Diğer bir deyişle, nehir suyunun bir noktadaki kalitesi; havzanın litolojisi, atmosferik ve antropojenik girdiler ve iklim koşulları gibi faktörlerin fonksiyonudur (Yu ve ark. 2010). Yüzey suları kirlilikten, özellikle atık suların bırakılmasından çok etkilenirler (Samarghandi ve ark. 2007; Zeeshan ve Azeez, 2016). 
Nehirler, bir havzanın ekolojik modellemesi, peyzaj düzenlemesi ve entegrasyonunda en önemli rol oynarlar. Nehirler geçtikleri yerlerdeki materyallerin özelliklerine bağlı olarak süspanse halde veya çözünmüş formda elementler taşırlar (Kumarasamy ve ark. 2014).

Şehirleşme, arazi kullanımındaki değişmeler, turizm gibi insan aktiviteleri ile jeoloji, iklim, ayrışma ve erozyon gibi doğal faktörler, yüzey sularında ciddi tehlikelere yol açarlar. Bu tehlikeler içme ve tarımsal amaçlı kullanıma zarar verebildiği gibi, aynı zamanda Yüksek düzeydeki ağır metaller hayvan ve insan sağlığında olumsuz etkilere neden olurlar. Bu nedenle yüzey su kimyası iz elementlerin sudaki dağılımının belirlenmesinde oldukça önemlidir (Rather ve ark. 2016; Singh ve ark. 2011).

Büyük Menderes nehrinin kalitesini belirlemek için yapılan bir çalışmada; elde edilen parametrelere göre, suyun en fazla Sarayköy ve Nazilli yörelerinde kirlenmiş olduğu belirlenmiştir (Küçük, 2007).

Gedik ve ark. (2010) tarafından yapılan bir çalışmada; Doğu Karadeniz Bölgesinde yer alan Fırtına Deresi'nin su kalitesi belirlenmiştir. Araştırma sonuçlarına göre; suyun saptanan tüm fiziksel ve kimyasal özelliklerine göre, yüksek kaliteli sınıfta yer aldığı belirlenmiştir.

Cicek ve Ertan (2012) tarafından yapılan bir çalışmada Isparta (Aksu) il sınırlarından doğup, Antalya (Serik)'da Akdeniz'e dökülen ve bölgenin önemli akarsularından biri olan Koprüçay Nehri'nin su niteliği araştırılmıştır. Araştırma sonuçlarına göre Koprüçay Nehri'nin fizikokimyasal değerlere göre birinci kalite sınıfında olduğu ancak dönemsel olarak kirlilik baskısında olduğu belirlenmiştir.

Güney Nijerya'da Cross nehir deltasında yapılan bir çalışmada, nehir sularının kimyasal bileşiminden sodyum adsorpsiyon oranı ve kalıcı sodyum karbonat değerleri bu suların sulama ve evsel kullanıma uygun, ancak sodyum yüzdesine göre sulamaya uygun olmadığı belirlenmiştir. Ayrıca, su kalite indeksi (WQI) sınıfları fakir ile mükemmel arasında değişmiştir (Edet ve ark., 2013).

Zhang ve ark. (2015) tarafından Himalaya bölgesinde yapılan bir çalışmada, alanda bulunan nehirlerin reaksiyonları orta ve yüksek alkali tepkimeli olup, $\mathrm{pH}^{\prime}$ ları 7.9-8.9 arasında değişmiştir. Ayrıca, TDS değerleri ile $\mathrm{Ca}$ ve $\mathrm{Mg}$ konsantrasyonları arasında pozitif bir ilişki bulunmuştur.

Singh ve ark. (2015) tarafından yapılan bir çalışmada, Varanasi'deki (Mısır) Varuna nehrinin su kalitesi incelenmiştir. Sonuçlar; ana bileşenler analizi (PCA) ve küme analizi (CA) gibi istatistik yöntemlerle değerlendirilmiştir. Çalışma sonunda, bazı su kalite parametreleri arasında istatistiksel açıdan önemli ilişkiler bulunmuştur.
Ma ve ark. (2015) tarafından güney Çin'deki Ashi nehir sularında azot (N) kirliliği araştırımıştır. Araştırma sonuçlarına göre, amonyum, nitrat ve toplam azot içeriği nehrin yukarı kesimlerinde diğer kesimlerden daha düşük bulunmuştur.

Mısır'da Rangit nehrinde yapılan bir çalışmada, nehir suyunun nötr-orta bazik reaksiyonlu olduğu ve iyonlardan $\mathrm{K}, \mathrm{Ca}, \mathrm{HCO}_{3}$ ve $\mathrm{SO}_{4}$ 'ün baskın olduğu belirlenmiştir (Gupta ve ark. 2016).

Bilgin ve Konanç (2016) tarafından Çoruh nehrinde yapılan bir çalışmada, su kalite parametrelerinin çoğunda, örnekleme noktaları arasındaki farklılık istatistiksel açıdan 0.05 düzeyinde önemli bulunmuştur. Ağca ve ark. (2018) tarafından yapılan bir çalışmada; Amik Ovası'nın yüzey sularının özelliklerinin belirlenmesi ve bunların içme ve sulama suyu kalitesi açısından değerlendirilmesi amaçlanmıştır. Analiz sonuçlarına göre, ortalama sıcaklık (T), toplam tuz (TT), $\mathrm{NO}_{3}, \mathrm{NH}_{4}, \mathrm{P}$, $\mathrm{Cu}, \mathrm{Mn}, \mathrm{Ni}, \mathrm{Pb}$ konsantrasyonları sırasıyla $23.8^{\circ} \mathrm{C}, \% 0.20$, $12.09 \mathrm{mg} \mathrm{L}^{-1}, 4.13 \mathrm{mg} \mathrm{L}^{-1}, 1.69 \mathrm{mg} \mathrm{L}^{-1}, 140.07 \mathrm{\mu g} \mathrm{L}^{-1}, 6.75$ $\mu \mathrm{g} \mathrm{L} \mathrm{L}^{-1}, 18.42 \mu \mathrm{g} \mathrm{L}^{-1}, 1.84 \mu \mathrm{g} \mathrm{L}^{-1}$ ve $4.43 \mu \mathrm{g} \mathrm{L}^{-1}$ olarak belirlenmiştir. Toplam 56 su örneğinden 52 tanesinin $T$ değerleri kaliteli sular için üst limit olarak belirlenen $25^{\circ} \mathrm{C}^{\prime}$ nin üzerinde belirlenmiştir. Ağır metal konsantrasyonları ve $P$ içerikleri, tüm örneklerde içme ve sulama suları için izin verilebilir maksimum sınırların altında bulunmuştur. Ayrıca, su örneklerinde $\mathrm{NO}_{3}$ ile $\mathrm{Cu}$ ve $\mathrm{Pb}$ arasında ve $\mathrm{NH}_{4}$ ile $\mathrm{P}$ ve $\mathrm{Mn}$ arasında önemli pozitif korelasyonlar bulunmuştur $(P<0.01)$.

Asi nehri ile ilgili geçmişte bazı çalışmalar yapılmıştır (Ödemiş ve ark. 2007; Özdilek ve Sangün, 2007; Ağca ve ark. 2009). Ancak bu çalışmalar çok detaylı değildir. Bu çalışmada, Amik ovası için çok önemli olan Asi nehir suyunun kalitesini etkileyen özellikler detaylı olarak belirlenmiş ve bu özellikler çeşitli yöntemler ile değerlendirilmiştir.

\section{MATERYAL ve YÖNTEM}

Asi nehri, Orta Doğu'nun en önemli su kaynaklarından birisidir. Nehir Lübnan'da doğar, Suriye ve Türkiye'ye doğru akar ve Samandağ'da Akdeniz'e dökülür. Toplam uzunluğu yaklaşık $380 \mathrm{~km}$ olan nehrin Türkiye'de kalan kısmı ise $88 \mathrm{~km}$ 'dir (Altunlu, 2002). Asi nehri aynı zamanda Amik ovasının en önemli sulama suyu kaynaklarından birisidir.

Bu çalışmada Asi nehrinin Türkiye'de kalan kısmında belirlenen 8 farklı noktadan (Şekil 1), 4 farklı dönemde (Mayıs 2017, Ağustos 2017, Kasım 2017 ve Şubat 2018) toplam 32 adet su örneği alınmıştır. Su örnekleri 1 litrelik temiz şişelere alınmış ve laboratuvarda mavi bant filtre kâğıdı ile süzülmüştür. Örnek alım sırasında ise su kapları 
alınacak su ile üç kez çalkalanmıştır. Katyon analizleri için alınacak örneklere, mikrobiyal bozulmayı önlemek için nitrik asit $\left(\mathrm{HNO}_{3}\right)$ eklenmiştir. Örnekler güvenli bir şekilde laboratuvara getirilerek, analiz edilene kadar buzdolabında $+4{ }^{\circ} \mathrm{C}^{\prime}$ de saklanmıştır.

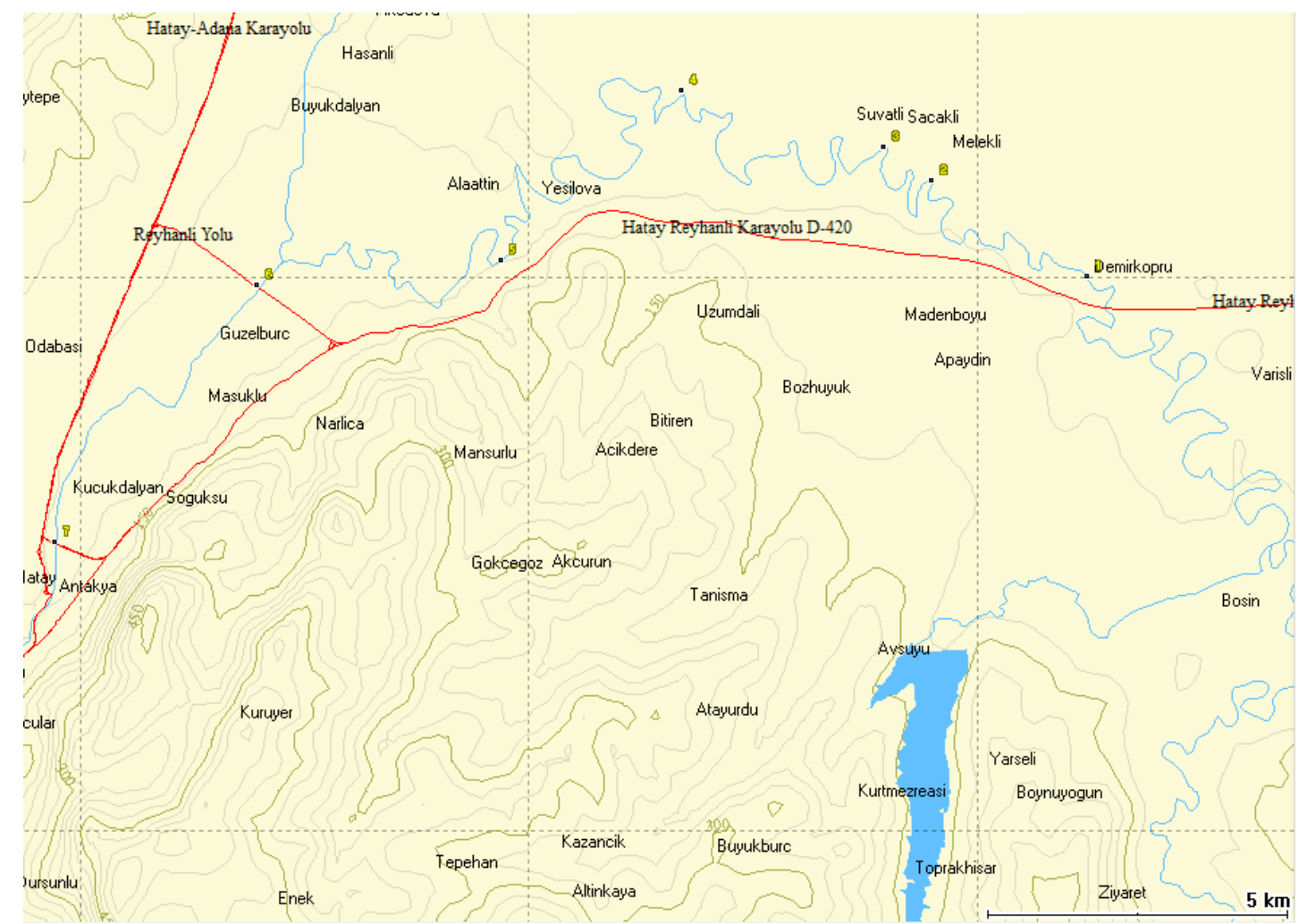

Şekil 1. Çalışma alanının coğrafi konumu ve su örneklerinin alındığı noktalar

Alınan su örneklerinde $\mathrm{pH}$, elektriksel iletkenlik (EC), eriyebilir katyon ( $\mathrm{Na}, \mathrm{K}, \mathrm{Ca}, \mathrm{Mg}$ ) ve eriyebilir anyon $\left(\mathrm{Cl}^{-}\right.$, $\left.\mathrm{CO}_{3}{ }^{-} \mathrm{HCO}_{3}{ }^{=}, \mathrm{SO}^{-}{ }_{4}\right)$ analizleri yapılmıştır. Her noktada ve her dönemde; $\mathrm{pH}$, elektriksel iletkenlik $(\mathrm{EC})$ ve klor $(\mathrm{Cl})$ parametreleri hemen örnekleme noktalarında YSI marka Proplus model su ölçüm cihazı ile ölçülmüştür.

Eriyebilir katyonlardan sodyum $(\mathrm{Na})$ ve potasyum $(\mathrm{K})$ fleymfotometre, kalsiyum (Ca) ve magnezyum $(\mathrm{Mg})$ ise atomik absorpsiyon spektrofotometresi ile tayin edilmiştir. Anyonlardan klor (Cl) gümüş nitrat titrasyonu, karbonat $\left(\mathrm{CO}_{3}\right)$ ve bikarbonat $\left(\mathrm{HCO}_{3}\right)$ sülfürik asit titrasyonu ile belirlenmiş, sülfat $\left(\mathrm{SO}_{4}\right)$ ise eriyebilir katyonların toplamından $\mathrm{Cl}, \mathrm{CO}_{3}$ ve $\mathrm{HCO}_{3}$ toplamının çıkartılması ile hesaplanmıştır (Richards, 1954).

Analiz edilmiş olan $\mathrm{Na}, \mathrm{Ca}$ ve $\mathrm{Mg}$ değerlerinden sodyum adsorpsiyon oranı (SAR), karbonat, bikarbonat, kalsiyum ve magnezyum değerlerinden kalıcı sodyum karbonat (RSC), kalsiyum ve magnezyum değerlerinden ise toplam sertlik (TH) ve magnezyum oranı (MR) gibi parametreler hesaplanmıştır. Hesaplanan, SAR, RSC, TH ve MR değerleri yorumlanarak suların kalitesi ve sınıflandırılması yapılmıştır. Bu değerlerin hesaplama formülleri aşağıda verilmiştir:
$\mathrm{SAR}=\mathrm{Na} / \mathrm{v}[(\mathrm{Ca}+\mathrm{Mg}) / 2] \quad$ Eq. $(1)$

$\mathrm{RSC}=\left(\mathrm{CO}_{3}+\mathrm{HCO}_{3}\right)-\left(\mathrm{Ca}^{+2}+\mathrm{Mg}^{+2}\right) \quad$ Eq. (2)

(Richards, 1954),

$\mathrm{TH}=\left(\mathrm{CaCO}_{3}\right.$ olarak, $\left.\mathrm{mg} / \mathrm{L}\right)=\left(\mathrm{Ca}^{+2}+\mathrm{Mg}^{+2}\right) \mathrm{me} / \mathrm{Lx} 50 \mathrm{Eq}$. (3) (Arumugam ve Elangovan, 2009)

$\mathrm{MR}=\mathrm{Mg}^{+2} \times 100 /\left(\mathrm{Ca}^{+2}+\mathrm{Mg}^{+2}\right)$ Eq. (4)

burada birimler $\mathrm{mg} \mathrm{L}^{-1}$ dir (Prasanth ve ark. 2012).

Su örneklerinin fizikokimyasal özelliklerindeki farklılıkları ve dağılımını açıklayabilmek için tanımlayıcı istatistiksel analiz (ortalama, en az, en fazla, varyasyon katsayısı, vb); su örneklerinin özellikleri arasındaki ilişkileri araştırmak için korelasyon analizi ve örnekleme dönemleri arasındaki farklılıkları açıklayabilmek için ise ANOVA (varyans analizi) ve DUNCAN testleri yapılmıştır. Ayrıca, suların sulama ve içme amaçlı kullanımları da araştırılmıştır. Tüm istatistik analizlerde SSPS 17.0 istatistik paket programı kullanılmıştır. 


\section{BULGULAR ve TARTIŞMA}

\section{Asi Nehir Suyunun Genel Özellikleri}

Asi nehir suyunun kalite parametrelerine ait tanımlayıcı istatistik analiz sonuçları Çizelge 1 'de verilmiştir. Nehir suyunun tüm örnekleme dönemi ve örnekleme noktalarındaki pH değerlerinin 7.72 (4. Dönem 1 nolu nokta) ile 9.0 (2. Dönem 6 nolu nokta), Na içeriklerinin 0.40 (1. Dönem 3 nolu nokta) ile $10.35 \mathrm{me} \mathrm{L}^{-1}$ (3. Dönem 8 nolu nokta), $\mathrm{K}$ içeriklerinin 0.12 (3. Dönem 4 nolu) ile $2.05 \mathrm{me} \mathrm{L}^{-1}$ (2. Dönem 7 nolu nokta) arasında, Ca içeriklerinin 0.52 (3. Dönem 7 nolu nokta) ile $4.27 \mathrm{me} \mathrm{L}^{-1}$ (4.Dönem 6 nolu nokta) arasında, $\mathrm{Mg}$ içeriklerinin 2.28 ile (2. Dönem 7 nolu nokta) ile $14.29 \mathrm{me} \mathrm{L}^{-1}$ (2. Dönem 6 nolu nokta) arasında, $\mathrm{Cl}$ içeriklerinin 0.98 (3. Dönem 3 nolu nokta) ile $6.47 \mathrm{me} \mathrm{L}^{-1}$ (3. Dönem 7 nolu nokta) arasında, $\mathrm{CO}_{3}$ içeriklerinin 0.6 (1. Dönem 1 nolu nokta) ile $2.4 \mathrm{me} \mathrm{L}^{-1}$ (2. Dönem 7 nolu nokta) arasında, $\mathrm{HCO}_{3}$ içeriklerinin 1.2 (1. Dönem 1 nolu nokta) ile $8.6 \mathrm{me} \mathrm{L}^{-1}(2$. Dönem 8 nolu nokta) arasında, $\mathrm{SO}_{4}$ içeriklerinin ise 0.15 (2. dönem 7 nolu nokta) ile $14.49 \mathrm{me} \mathrm{L}^{-1}$ (3. Dönem 8 nolu nokta) arasında değiştiği görülmektedir (Çizelge 1). Yine, su örneklerinde TH değerleri $152.01 \mathrm{mg} \mathrm{L}^{-1}$ (2. Dönem 7 nolu nokta) ile $880.33 \mathrm{mg} \mathrm{L}^{-1}$ (2. Dönem 6 nolu nokta), MR değerleri ise \% 35.72 ( 4. Dönem 5 nolu nokta) ile \% 91.77 (3. Dönem 7 nolu nokta) arasında değişmiştir (Çizelge 1).

Çizelge 1. Örnekleme dönemlerine göre Asi nehri su kalite parametrelerine ait tanımlayııı istatistik analiz sonuçları ve Duncan test gruplandırmaları

\begin{tabular}{|c|c|c|c|c|c|c|}
\hline Özellik & Dönem & En düşük & En yüksek & Ortalama & $\begin{array}{c}\text { Standart } \\
\text { sapma }\end{array}$ & $\begin{array}{c}\text { Varyasyon } \\
\text { katsayısı }\end{array}$ \\
\hline \multirow{5}{*}{$\mathrm{EC}(\mu \mathrm{S} \mathrm{cm}-1)$} & 1 & 998 & 1531 & 1182.62 & 214.97 & 18.17 \\
\hline & 2 & 887 & 1123 & 1029.50 & 74.72 & 7.25 \\
\hline & 3 & 999 & 1663 & 1175.37 & 293.97 & 25.00 \\
\hline & 4 & 1034 & 1072 & 1053.62 & 13.47 & 1.27 \\
\hline & Toplam & 887 & 1663 & 1110.28 & 190.28 & 17.14 \\
\hline \multirow{5}{*}{$\mathrm{pH}$} & 1 & 7.92 & 8.50 & $8.16(a b)$ & 0.23 & 2.80 \\
\hline & 2 & 8 & 9.00 & 8.42 (c) & 0.30 & 3.50 \\
\hline & 3 & 8.06 & 8.53 & $8.22(b c)$ & 0.15 & 1.78 \\
\hline & 4 & 7.72 & 8.10 & 7.97 (a) & 0.14 & 1.76 \\
\hline & Toplam & 7.72 & 9.00 & 8.19 & 0.26 & 3.17 \\
\hline \multirow{5}{*}{$\mathrm{Cl}\left(\mathrm{me} \mathrm{L}^{-1}\right)$} & 1 & 1.86 & 3.53 & 2.40 & 0.67 & 49.57 \\
\hline & 2 & 2.17 & 3.36 & 3.03 & 0.39 & 75.67 \\
\hline & 3 & 0.98 & 6.47 & 2.39 & 2.43 & 64.95 \\
\hline & 4 & 1.77 & 2.58 & 2.07 & 0.28 & 33.33 \\
\hline & Toplam & 0.98 & 6.47 & 2.47 & 1.27 & 56.98 \\
\hline \multirow{5}{*}{$\mathrm{Na}\left(\mathrm{me} \mathrm{L}^{-1}\right)$} & 1 & 0.40 & 5.55 & 3.51 & 1.74 & 314.28 \\
\hline & 2 & 0.60 & 7.70 & 3.33 & 2.52 & 116.36 \\
\hline & 3 & 1.77 & 10.35 & 4.28 & 2.78 & 55.55 \\
\hline & 4 & 2.11 & 5.43 & 3.48 & 1.16 & 37.03 \\
\hline & Toplam & 0.40 & 10.35 & 3.65 & 2.08 & 103.03 \\
\hline \multirow{5}{*}{$\mathrm{K}\left(\mathrm{me} \mathrm{L}^{-1}\right)$} & 1 & 0.13 & 0.32 & 0.21 & 0.66 & 39.75 \\
\hline & 2 & 0.12 & 2.05 & 0.55 & 0.64 & 35.26 \\
\hline & 3 & 0.12 & 0.58 & 0.27 & 0.15 & 32.74 \\
\hline & 4 & 0.18 & 0.43 & 0.27 & 0.1 & 39.40 \\
\hline & Toplam & 0.12 & 2.05 & 0.33 & 0.34 & 43.56 \\
\hline \multirow{5}{*}{$\mathrm{Ca}\left(\mathrm{me} \mathrm{L}^{-1}\right)$} & 1 & 0.95 & 2.57 & 1.66 & 0.66 & 35.15 \\
\hline & 2 & 0.76 & 3.32 & 2.41 & 0.85 & 51.86 \\
\hline & 3 & 0.52 & 3.99 & 2.55 & 1.09 & 41.57 \\
\hline & 4 & 1.18 & 4.27 & 3.02 & 1.19 & 36.51 \\
\hline & Toplam & 0.52 & 4.27 & 2.41 & 1.05 & 43.82 \\
\hline
\end{tabular}


Çizelge 1. Devamı

\begin{tabular}{|c|c|c|c|c|c|c|}
\hline & 1 & 4.79 & 11.23 & 8.25 & 2.90 & 27.90 \\
\hline & 2 & 2.28 & 14.29 & 7.50 & 3.89 & 12.87 \\
\hline \multirow[t]{5}{*}{$\mathrm{Mg}\left(\mathrm{me} \mathrm{L}^{-1}\right)$} & 3 & 3.51 & 13.53 & 8.37 & 3.48 & 101.66 \\
\hline & 4 & 3.05 & 8.26 & 5.34 & 1.95 & 13.52 \\
\hline & Toplam & 2.28 & 14.29 & 7.37 & 3.23 & 194.48 \\
\hline & 1 & 0.60 & 1.20 & 0.90 & 0.26 & 346.15 \\
\hline & 2 & 0.80 & 2.40 & 1.17 & 0.55 & 47.00 \\
\hline \multirow[t]{5}{*}{$\mathrm{CO}_{3}\left(\mathrm{me} \mathrm{L}^{-1}\right)$} & 3 & 0.80 & 1.20 & 1.10 & 0.19 & 17.27 \\
\hline & 4 & 0.80 & 1.60 & 1.25 & 0.26 & 20.80 \\
\hline & Toplam & 0.60 & 2.40 & 1.11 & 0.35 & 31.53 \\
\hline & 1 & 1.20 & 2.20 & 1.70 & 0.37 & 21.76 \\
\hline & 2 & 2.20 & 8.60 & 3.65 & 2.07 & 56.72 \\
\hline \multirow[t]{5}{*}{$\mathrm{HCO}_{3}\left(\mathrm{me} \mathrm{L}^{-1}\right)$} & 3 & 2.40 & 6 & 3.65 & 1.31 & 35.89 \\
\hline & 4 & 2.80 & 6.80 & 3.85 & 1.33 & 34.54 \\
\hline & Toplam & 1.20 & 8.60 & 3.21 & 1.61 & 50.15 \\
\hline & 1 & 4.31 & 14.14 & 8.64 & 4.12 & 60.45 \\
\hline & 2 & 0.15 & 12.65 & 5.94 & 4.61 & 77.60 \\
\hline \multirow[t]{5}{*}{$\mathrm{SO}_{4}\left(\mathrm{me} \mathrm{L}^{-1}\right)$} & 3 & 1.26 & 14.49 & 8.32 & 5.03 & 60.45 \\
\hline & 4 & 1.32 & 10.71 & 4.94 & 3.51 & 71.05 \\
\hline & Toplam & 0.15 & 14.49 & 6.96 & 4.43 & 63.64 \\
\hline & 1 & 0.16 & 2.21 & 1.59 & 0.66 & 41.50 \\
\hline & 2 & 0.24 & 3.11 & 1.59 & 1.01 & 63.52 \\
\hline \multirow[t]{5}{*}{ SAR } & 3 & 0.78 & 3.53 & 1.77 & 0.84 & 47.45 \\
\hline & 4 & 1.24 & 2.19 & 1.68 & 0.35 & 20.83 \\
\hline & Toplam & 0.16 & 3.53 & 1.66 & 0.72 & 43.37 \\
\hline & 1 & 308.00 & 689.75 & 459.50 & 166.88 & 36.32 \\
\hline & 2 & 152.01 & 880.33 & 495.63 & 232.20 & 46.85 \\
\hline \multirow[t]{5}{*}{$\mathrm{TH}\left(\mathrm{mg} \mathrm{L}^{-1}\right)$} & 3 & 272.38 & 859.00 & 545.83 & 199.81 & 36.60 \\
\hline & 4 & 260.83 & 614.08 & 417.93 & 120.40 & 28.80 \\
\hline & Toplam & 152.01 & 880.33 & 488.72 & 181.42 & 37.12 \\
\hline & 1 & 65.26 & 86.22 & 74.49 & 6.52 & 8.75 \\
\hline & 2 & 55.77 & 72.12 & 63.64 & 5.90 & 9.27 \\
\hline \multirow[t]{3}{*}{ MR (\%) } & 3 & 50.38 & 91.77 & 65.04 & 13.27 & 20.40 \\
\hline & 4 & 35.72 & 76.22 & 51.92 & 13.65 & 26.29 \\
\hline & Toplam & 35.72 & 91.77 & 63.77 & 12.87 & 20.18 \\
\hline
\end{tabular}

Tüm noktalardan ve bütün dönemlerde alınan örneklerin özelliklerinin ortalamaları değerlendirildiğinde, katyonlardan $\mathrm{Mg}$ baskın olup, bunu sırasıyla $\mathrm{Na}$, Ca ve $\mathrm{K}$ izlemiştir. Yine ortalama değerlere göre, anyonlardan sülfat $\left(\mathrm{SO}_{4}\right)$ baskın olup bunu sırasıyla bikarbonat $\left(\mathrm{HCO}_{3}\right)$, klor $(\mathrm{Cl})$ ve karbonat $\left(\mathrm{CO}_{3}\right)$ izlemiştir.

Yapılan varyans analiz sonuçlarına göre; örnekleme noktaları arasında EC değerlerindeki farklılık istatistiksel açıdan \% 5 düzeyinde önemli bulunmuştur. Diğer parametrelerdeki farklııklar ise istatistiksel açıdan önemli bulunmamıştır. Yine, örnekleme dönemleri arasında ise $\mathrm{pH}, \mathrm{HCO}_{3}$ ve MR değerleri arasındaki farklııı $\% 1$ düzeyinde önemli bulunmuştur (Çizelge 2). Benzer sonuçlar Ağca ve ark. (2009) tarafından da belirlenmiştir.

\section{Asi Nehir Suyu Kalitesinin İçme Amaçlı Kullanımının Değerlendirilmesi}

Asi nehir suyunun fiziko-kimyasal özellikleri Dünya Sağlık Örgütü (WHO, 1997) tarafından önerilen standart değerler ile kıyaslanarak içme amaçlı uygunluğu değerlendirilmiştir.

Su örneklerinden 3 tanesinin $\mathrm{pH}$ değeri, içme suları için arzu edilen üst sınır olan $8.5^{\prime}$ in üzerinde bulunmuştur. Yine örneklerin tamamının EC değerleri en fazla arzu edilen limit değerin $\left(750 \mu \mathrm{S} \mathrm{cm}^{-1}\right)$ üzerinde, üç tanesi ise maksimum izin verilebilir sınır olan $1500 \mu \mathrm{S} \mathrm{cm}{ }^{-1}$ nin üzerinde olduğu belirlenmiştir.

$\mathrm{Su}$ örneklerinin 8 tanesinde $\mathrm{Na}$ konsantrasyonu arzu edilen üst sınır olan $2.17 \mathrm{me} \mathrm{L}^{-1}$ 'nin, 1 tanesi ise izin verilen en yüksek sınır olan $8.70 \mathrm{me} \mathrm{L}^{-1}$ nin üzerinde bulunmuştur. 
Çizelge 2. Su özelliklerinin dönemler ve noktalar arası varyans analiz sonuçları

\begin{tabular}{cccccc}
\hline Özellik & Dönemler arası & & & Noktalar arası & \\
$\mathrm{EC}$ & $\mathbf{F}$ & $\mathbf{P}$ & Özellik & $\mathbf{F}$ & $\mathbf{P}$ \\
$\mathrm{pH}$ & 1.48 & 0.24 & $\mathrm{EC}$ & 2.73 & $\mathbf{0 . 0 3}$ \\
$\mathrm{Na}$ & 5.86 & $\mathbf{0 . 0 0 * *}$ & $\mathrm{pH}$ & 1.51 & 0.21 \\
$\mathrm{~K}$ & 0.32 & 0.81 & $\mathrm{Na}$ & 1.83 & 0.13 \\
$\mathrm{Ca}$ & 1.69 & 0.19 & $\mathrm{~K}$ & 1.15 & 0.37 \\
$\mathrm{Mg}$ & 2.71 & 0.06 & $\mathrm{Ca}$ & 1.95 & 0.11 \\
$\mathrm{Cl}$ & 1.60 & 0.21 & $\mathrm{Mg}$ & 0.51 & 0.82 \\
$\mathrm{CO}_{3}$ & 0.78 & 0.51 & $\mathrm{Cl}$ & 1.14 & 0.37 \\
$\mathrm{HCO}_{3}$ & 1.54 & 0.23 & $\mathrm{CO}_{3}$ & 0.89 & 0.53 \\
$\mathrm{SO}_{4}$ & 4.15 & $\mathbf{0 . 0 2 *}$ & $\mathrm{HCO}_{3}$ & 1.22 & 0.33 \\
$\mathrm{SAR}$ & 1.38 & 0.27 & $\mathrm{SO}_{4}$ & 0.72 & 0.65 \\
$\mathrm{TH}$ & 0.10 & 0.96 & $\mathrm{SAR}$ & 1.66 & 0.17 \\
$\mathrm{MR}$ & 0.65 & 0.59 & $\mathrm{TH}$ & 0.79 & 0.61 \\
\end{tabular}

**0.01 düzeyinde önemli, * 0.05 düzeyinde önemli

Diğer örneklerin $\mathrm{Na}$ içerikleri ise 2.17-8.70 me $\mathrm{L}^{-1}$ arasındadır. Asi nehrinden tüm noktalardan ve tüm dönemlerde alınan su örneklerinin tamamında $\mathrm{K}$ içeriği önerilen sınırın ( $\left.2.55 \mathrm{me} \mathrm{L}^{-1}\right)$ altında bulunmuştur. $4 \mathrm{su}$ örneğinin $\mathrm{Ca}$ içeriği arzulanan en fazla değerin (3.75 me $\mathrm{L}^{-1}$ ) üstünde, tüm su örneklerinin Ca içeriği ise maksimum izin verilen değerin (10 me $\left.\mathrm{L}^{-1}\right)^{\prime}$ 'nin altında olduğu belirlenmiştir. Örneklerden bir tanesinin $\mathrm{Mg}$ içeriği arzulanan en fazla değerin $\left(2.5 \mathrm{me} \mathrm{L}^{-1}\right)$ altında, 2 tanesi ise maksimum izin verilen sınır değerin $\left(12.5 \mathrm{me} \mathrm{L}^{-1}\right)^{\prime}$ nin üzerinde bulunmuştur. Diğer örneklerin $\mathrm{Mg}$ konsantrasyonları ise bu iki sınır değer arasında kalmıştır. $\mathrm{Su}$ örneklerinin yirmi bir tanesinin $\mathrm{HCO}_{3}$ içeriği, arzu edilen maksimum içeriğin ( $3.28 \mathrm{me}^{-1}$ ) altında, diğerleri ise bu sınır değer ile maksimum izin verilebilir sınır değer olan 9.84 me $\mathrm{L}^{-1}$ nin arasında olduğu saptanmıştır. Örneklerin tamamının $\mathrm{Cl}$ içerikleri, arzu edilen maksimum değerin (7.04 $\mathrm{me} \mathrm{L}^{-1}$ ) altında bulunmuştur. On bir örneğin $\mathrm{SO}_{4}$ içeriği arzu edilen en üst sınır değerin ( $4.17 \mathrm{me} \mathrm{L}^{-1}$ ) altında, 5 tanesi ise maksimum izin verilen sınır değerin (12.5 me $\mathrm{L}^{-1}$ ) üzerinde, diğerleri ise bu iki sınır değerin arasında bulunmuştur

\section{Asi Nehir Suyu Kalitesinin Sulama Amaçlı Kullanımının Değerlendirilmesi}

Asi nehir suyunun EC değerleri 887 (2. Dönem birinci

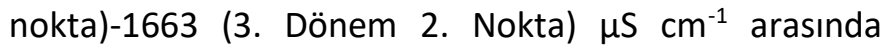
değişmiştir. Nehir suyunun SAR değerleri ise 0.16 (1. Dönem 3 nolu nokta) - 3.53 (3. Dönem 2 nolu nokta) arasında değişmiştir (Çizelge 1). Bu sonuçlara göre Asi Nehir suyunun Amerikan Tuzluluk Laboratuvarı sınıflandırma sistemine göre (Richards 1954), sulama suyu açısından kalite sınıfı tüm nokta ve bütün dönemlerde C3S1 (yüksek tuz ve düşük sodyum tehlikesi) olarak belirlenmiştir. Benzer sonuçlar Ağca ve ark. (2009) ve Ödemiş ve ark. (2007) tarafından da elde edilmiştir. Goher ve ark. (2014) tarafından Nil nehrinde yapılan bir çalışmada, nehir suyunun EC değeri $350-544 \mu \mathrm{S} \mathrm{cm}{ }^{-1}$ arasında bulunmuştur. Bu suyun tuz içeriği yüksek olduğundan sulamada kullanılırken dikkatli olunması gerekir. EC değerleri sulardaki tuzluluk düzeyinin bir ölçüsüdür. Asi nehir suyunun EC değerleri her ne kadar 887-1663 $\mu \mathrm{S} \mathrm{cm}^{-1}$ arasında olup C3 Sulama suyu sınıfı içerisinde yer alsa da, kötü bir sulama suyu olduğundan söz edilemez. Bazı tuza duyarlı (hassas) olan bitkiler bile $1600 \mu \mathrm{S} \mathrm{cm} \mathrm{cm}^{-1}$ EC'ye kadar tuz içeren sulara toprak bünyesi ve drenaj koşullarına bağlı olarak zarar görmeden dayanabilmektedir. Bu nedenle bu suyun kullanıldığı topraklarda iyi bir tuz yıkamasının sağlanabilmesi için mutlaka yeterli drenaj sisteminin kurulması gereklidir. Asi nehir suyunun sulamada sodyumluluk yönünden ise herhangi bir sorunu yoktur. Diğer bir deyişle, Asi nehir suyu hemen hemen tüm topraklarda kullanılabilir. Ancak taş çekirdekli meyveler ve avokado gibi sodyuma duyarlı bitkilerde sodyum zararlı konsantrasyonlara kadar birikebilmektedir (Richards, 1954).

Tüm örnekleme noktalarında ve örnekleme zamanlarında alınan örneklerin hemen hemen tamamında RSC değerleri sulama suyu açısından kaliteli sular için kiriter olan $1.25 \mathrm{me} \mathrm{L}^{-1}$ 'nin (Eaton, 1950) altında bulunmuştur. Üstelik bir dönemde bir noktadan alınan örnek dışında tüm örneklerde RSC saptanamamıştır. Ağca ve ark. (2018) da Amik ovası yeraltı sularında bu konuda benzer sonuçlar bulmuşlardır. Yine Kumudumali ve Nirmaneee (2019) tarafından Sri Lanka'da yapılan çalışmada da yüzey sularının RSC değerleri çok düşük bulunmuştur. 
Sulama sularında magnezyum tehlikesi magnezyum oranı (MR) değerlerine göre sınıflandırılmaktadır. Bu sınıflamada MR değerleri \% 50'nin üzerinde olan sular sulama için uygun değildir (Prasanth ve ark., 2012). Bu sınıflamaya göre su örneklerinin ancak 4 tanesinde MR değeri \% 50' den düşük bulunmuştur.

\section{Asi Nehir Suyu Özellikleri Arasındaki Korelasyon}

Alınan su örneklerinin özellikleri arasındaki korelasyon katsayıları Çizelge 3 'de verilmiştir. SAR ile Na arasında istatistiksel açıdan çok yüksek pozitif bir ilişki belirlenmiştir. Bu durum da SAR'ın direk olarak $\mathrm{Na}$ değerleri ile ilişkili olmasından kaynaklanmaktadır. Zira sudaki toplam katyonlar içindeki Na iyon konsantrasyonu arttıkça, $\mathrm{Ca}$ ve $\mathrm{Mg}$ iyonlarının konsantrasyonları düşmektedir. Bu nedenle SAR değerleri artmaktadır. Magnezyum oranı (MR) ile $\mathrm{Mg}$ arasında istatistiksel açıdan \% 1 düzeyinde pozitif, $\mathrm{Ca}$ arasında ise \% 1 düzeyinde negatif korelasyon bulunmuştur (Çizelge 3 ). $\mathrm{Bu}$ durum da $\mathrm{Mg}$ değerleri arttıkça MR değerlerinin de artmasından, $\mathrm{Ca}$ değerlerinin artması ile ise azalmasından kaynaklanmaktadır. Yine RSC ile $\mathrm{Mg}$ arasında çok kuvvetli ve istatitiksel açıdan önemli $\left(r^{2}=-\right.$ 0.906) negatif korelasyon bulunmuştur. Bu da sularda Mg konsantrasyonu arttıkça RSC değerinin azalmasından kaynaklanmıştır. Toplam sertlik (TH) ile $\mathrm{Ca}$ ve $\mathrm{Mg}$ arasında \% 1 düzeyinde istatistiksel açıdan önemli bir korelasyon bulunması (Çizelge 3), sulardaki toplam sertliğin bu iyonlardan kaynaklandığını göstermektedir. Sudaki $\mathrm{K}$ değerleri ile $\mathrm{CO}_{3}$ ve $\mathrm{NH}_{4}$ iyonları dışında, diğer iyonlarla önemli bir ilişki belirlenememiştir. Örneklerin $\mathrm{Cl}$ içerikleri ile EC, TDS, tuz ve $\mathrm{pH}^{\prime}$ ları arasında istatistiksel açıdan 0.05 düzeyinde önemli pozitif ilişkiler belirlenmiştir.

Çizelge 3. Su parametreleri arasındaki korelasyon katsayıları

\begin{tabular}{|c|c|c|c|c|c|c|c|c|c|c|c|c|}
\hline & $\mathrm{Na}$ & $\mathrm{K}$ & $\mathrm{Ca}$ & $\mathrm{Mg}$ & $\mathrm{Cl}$ & $\mathrm{CO}_{3}$ & $\mathrm{HCO}_{3}$ & $\mathrm{SO}_{4}$ & SAR & $\mathrm{EC}$ & $\mathrm{pH}$ & $\mathrm{TH}$ \\
\hline K & 0.075 & & & & & & & & & & & \\
\hline $\mathrm{Ca}$ & $0.357^{*}$ & -0.208 & & & & & & & & & & \\
\hline $\mathrm{Mg}$ & $0.413^{*}$ & -0.050 & 0.243 & & & & & & & & & \\
\hline $\mathrm{Cl}$ & 0.173 & 0.199 & -0.144 & 0.271 & & & & & & & & \\
\hline $\mathrm{CO}_{3}$ & 0.036 & $0.679^{* *}$ & 0.084 & -0.106 & 0.035 & & & & & & & \\
\hline $\mathrm{HCO}_{3}$ & $0.469^{* *}$ & 0.111 & $0.530^{* *}$ & 0.193 & 0.107 & 0.274 & & & & & & \\
\hline $\mathrm{SO}_{4}$ & $0.637^{* *}$ & -0.123 & $0.407^{*}$ & $0.837^{* *}$ & -0.069 & -0.176 & 0.079 & & & & & \\
\hline SAR & $0.937^{* *}$ & 0.216 & 0.199 & 0.119 & 0.101 & 0.139 & $0.393^{*}$ & $0.407^{*}$ & & & & \\
\hline $\mathrm{EC}$ & 0.300 & 0.044 & -0.220 & 0.194 & $0.772^{* *}$ & 0.013 & 0.000 & 0.010 & 0.274 & & & \\
\hline $\mathrm{pH}$ & -0.082 & 0.271 & -0.118 & 0.235 & $0.486^{* *}$ & 0.123 & -0.130 & 0.024 & -0.083 & $0.364^{*}$ & & \\
\hline RSC & -0.266 & 0.224 & -0.268 & $-0.906^{* *}$ & -0.152 & 0.295 & 0.148 & $-0.864^{* *}$ & 0.025 & -0.110 & -0.226 & \\
\hline TH & $0.471^{* *}$ & -0.104 & $0.505^{* *}$ & $0.960^{* *}$ & 0.200 & -0.070 & 0.325 & $0.862^{* *}$ & 0.163 & 0.109 & 0.175 & \\
\hline MR & 0.074 & 0.148 & $-0.603^{* *}$ & $0.595^{* *}$ & 0.323 & -0.172 & -0.258 & $0.353^{*}$ & -0.025 & 0.340 & 0.270 & $0.356^{*}$ \\
\hline
\end{tabular}

**Korelasyon 0.01 düzeyinde önemli, * korelasyon 0.05 düzeyinde önemli

Asi nehri Amik Ovası'nın tarımsal sulamalar için en önemli yüzey su kaynağıdır. Nehir suyu, hem Türkiye hem de Suriye'de özellikle yaz aylarında yoğun sulamalar nedeniyle belirgin bir şekilde azalmaktadır. Bu nedenle de suyun kalitesi çok önem taşımaktadır.

Asi nehir suyunda katyonların baskınlık sırası çoktan aza doğru $\mathrm{Mg}>\mathrm{Na}>\mathrm{Ca}>\mathrm{K}$ şeklinde, anyonların baskınlık sırası ise $\mathrm{SO}_{4}>\mathrm{HCO}_{3}>\mathrm{Cl}>\mathrm{CO}_{3}$ şeklindedir. Bu sıralamaya göre baskın tuz çeşidi ise magnezyum sülfat $\left(\mathrm{MgSO}_{4}\right)^{\prime}$ tır.

Su örneklerinin 3 tanesi hariç, pH değerleri alkalilik sınırı olan $8.5^{\prime}$ in altında ölçülmüştür. Bu durumu baskın tuz çeşidi $\left(\mathrm{MgSO}_{4}\right)$ de teyit etmektedir. Zira magnezyum sülfat kuvvetli bir asit ve kuvvetli bir bazdan oluşan bir tuzdur. Bu tip tuzlar ise hidroliz olmadıklarından ortam $\mathrm{pH}^{\prime}$ sını yükseltemezler. Ayıca, suların SAR ve RSC değerlerinin de oldukça düşük olduğu, hatta çoğunda RSC değerlerinin olmadığı belirlenmiştir. Bu durum, Asi nehir suyunun topraklarda alkalilik açısından herhangi bir sorun oluşturmayacağını göstermektedir. Diğer yandan, su örneklerinin tuzluluk değerlerinin (EC değerleri) yüksek olduğu görülmektedir. Asi nehir suyu tuzluluk açısından çok tuzlu sular sınıfına girmektedir. Bu su ancak iyi drenaj koşullarında ve tuzluluk kontrolü için özel yönetim uygulamaları ile sulamada kullanılabilir. Bu nedenle Asi nehir suyunu sulama amaçlı kullanırken dikkatli olmak gerekir. Zira topraklardaki tuz kaynaklarından birisi de sulama sularıdır.

Asi nehir suyunun $\mathrm{Mg}$ içerikleri $\mathrm{Ca}$ içeriklerine göre oldukça yüksek bulunmuştur. Magnezyum aslında bir makro besin elementidir. Ancak fazlalığı toprakta ve bitkilerde bazı sorunlara neden olmaktadır. Magnezyum fazlalığının en önemli olumsuz etkisi bitkilerin $\mathrm{K}$ ve $\mathrm{Ca}$ alımını engellemesidir. Yine aşırı miktarda magnezyum bitkilerde kuraklık stresinde fotosentezi ve bitki büyümesini önler (Karaman, 2012). Bu nedenle MR değerleri bu suyun sulama amaçlı kullanımını oldukça sınırlamaktadır. Ancak, Asi nehir suyu magnezyum eksikliğine duyarlı olan bağ, turunçgiller, şekerpancarı, 
patates, domates ve soğan gibi bitkilerin yetiştirildiği ve magnezyum içeriği az olan toprakların sulanmasında kullanılabilir.

\section{ÖZET}

Amaç: Bu çalışmada, Türkiye'nin sınır aşan akarsularından biri olan Asi Nehrinin su kalite parametre düzeylerinin belirlenmesi ve bunların içme ve sulama suyu kalitesi açısından değerlendirilmesi amaçlanmıştır.

Yöntem ve Bulgular: Bu çalışmada, Asi Nehrinin Türkiye kısmında belirlenen 8 noktadan, dört farklı dönemde su örnekleri alınmıştır. Alınan su örneklerinde $\mathrm{pH}$, elektriksel iletkenlik ( $\mathrm{EC}$ ), eriyebilir katyon ( $\mathrm{Na}, \mathrm{K}, \mathrm{Ca}, \mathrm{Mg}$ ) ve eriyebilir anyon $\left(\mathrm{Cl}^{-}, \mathrm{SO}_{4}, \mathrm{CO}_{3}{ }^{-}\right.$ve $\left.\mathrm{HCO}_{3}{ }^{-}\right)$analizleri yapılmıştır. Ayrıca eriyebilir katyon ve anyonlardan sodyum adsorpsiyon oranı (SAR), magnezyum oranı (MR), toplam sertlik (TH) ve kalıc bikarbonat (RSC) değerleri hesaplanmıştır. Araştırma konusu su kaynaklarına ait bütün parametrelerin tanımlayıcı istatistik analizleri (ortalama, en düşük ve en yüksek değerler, standart sapma, varyasyon katsayısı, vb.) hesaplanmıştır. Su örneklerinin özellikleri arasındaki ilişkileri araştırmak için korelasyon analizi ve örnekleme dönemleri ve noktaları arasındaki farklııkları açıklayabilmek için ise anova ve duncan testleri yapılmıştır. Asi Nehir suyunda katyonların oransal bolluk sıralaması çoktan aza doğru $\mathrm{Mg}>\mathrm{Na}>\mathrm{Ca}>\mathrm{K}$ şeklinde, anyonların sıralaması ise $\mathrm{SO} 4>\mathrm{HCO}_{3}>\mathrm{Cl}>\mathrm{CO}_{3}$ şeklinde belirlenmiştir. Amerikan tuzluluk laboratuvarı diyagramına göre, Asi Nehir suyunun kalite sınıfı $C_{3} S_{1}$ olarak belirlenmiştir.

Genel Yorum: Yapılan varyans analiz sonuçlarına göre; örnekleme noktaları arasında EC değerlerindeki farklııı istatistiksel açıdan \%5 düzeyinde önemli bulunmuştur. Diğer parametrelerdeki farklılıklar ise istatistiksel açıdan önemli bulunamamıştır. Yine, örnekleme dönemleri arasında ise $\mathrm{pH}, \mathrm{HCO}_{3}$ ve $\mathrm{MR}$ değerleri arasındaki farklılık \%1 düzeyinde önemli bulunmuştur.

Çalışmanın Önemi ve Etkisi: Asi nehir suyunu kullanırken dikkatli olmak gerekir. Asi nehir suyu tuzluluk açısından çok tuzlu sular sınıfına girmektedir. Bu su ancak iyi drenaj koşullarında ve tuzluluk kontrolü için özel yönetim uygulamaları ile sulamada kullanılabilir.

Anahtar Kelimeler: Asi nehri, Su kalitesi, fiziko-kimyasal özellikler.

\section{TEŞEKKÜR}

Bu çalışmaya maddi destek sağlayan Hatay Mustafa Kemal Üniversitesi Bilimsel Araştırmalar Proje Koordinatörlüğüne teşekkür ederiz (Proje No: 16580).

\section{ÇIKAR ÇATIŞMA BEYANI}

Yazar(lar) çalışma konusunda çıkar çatışmasının olmadığını beyan eder.

\section{ARAŞTIRMACILARIN KATKI ORANI BEYANI}

Yazarlar, çalışmaya Necat AĞCA (\%65) ve Kemal DOĞAN (\%35) oranlarında katkı sağlamış olduklarını beyan eder.

\section{KAYNAKLAR}

Ağca N, Ödemiş B, Yalçin M (2009) Spatial and temporal variations of water quality parameters in Orontes river Hatay. Turkey. Fresenius Environ. Bull. 18 (4): 457-460.

Ağca N, Doğan K, Karanlık S (2018) Amik ovasındaki yüzey sularında amonyum, nitrat, fosfor ve ağır metal kirliliğinin belirlenmesi. MKÜ Zir. Fak. Derg. 23(2):197-203.

Arumugam K, Elangovan K (2009) Hydrochemical characteristics and groundwater quality assessment in Tirupur Region, Coimbatore District, Tamil Nadu, India. Environ. Geol. 58:1509-1520.

Altunlu E (2002) Potential water resources of Hatay. Published in Has Pipe Company.

Bilgin A, Konanç MU (2016) Evaluation of surface water quality and heavy metal pollution of Coruh River Basin (Turkey) by multivariate statistical methods. Environ Earth Sci 75: 1029.

Cicek NL, Ertan OO (2012) Köprüçay nehri (Antalya)'nın fiziko-kimyasal özelliklerine göre su kalitesinin belirlenmesi. Ekoloji 21(84):54-65.

Gedik K, Verep B, Terzi E, Fevzioğlu S (2010) Fırtına Deresi (Rize)'nin fiziko-kimyasal açıdan su kalitesinin belirlenmesi. Ekoloji, 19 (76): 25-35.

Eaton FM (1950) Significance of carbonates in irrigation water. Soil. Sci. 69: 123-133.

Edet A, Ukpong A, Nganje T (2013) Hydrochemical studies of Cross River Basin (southeastern Nigeria) river systems using cross plots, statistics and water quality index. Environ. Earth Sci. 70:3043-3056.

Goher ME, Hassan AM, Abdel-Moniem IA, Fahmy AH, ElSayed SM (2014) Evaluation of surface water quality and heavy metal indices of Ismailia Canal, Nile River, Egypt. Egypt. J. Aquat. Res. 40: 225-233.

Gupta S, Nayek S, Chakraborty D (2016) Hydrochamical evaluation of Rangit river, Sikkim, India: using Water Quality Index and multivariate statistics. Environ. Earth Sci. 75:67.

Karaman MR (2012) Bitki Besleme. Gübretaş Rehber Kitaplar Dizisi: 2. Ankara, 1066 S. 
Kumarasamy $\mathrm{P}$, James RA, Dahms HU, Byeon WC, Ramesh R (2014) Multivariate water quality assessment from the Tamiraparani river basin. Soutern India. Environ. Earth Sci. 71:2441-2451.

Kumudumali MMLU, Nirmanee KGS (2019) Assessment of surface water quality for irrigation in Ulagalla Cascade, Sri Lanka. Int. J. Lat. Technol. Enginer. Manag. Appl. Sci. (IJLTEMAS) 8: 1-5.

Küçük S (2007) Büyük Menderes nehri su kalitesi ölçümlerinin su ürünleri açısından incelenmesi. ADÜ Zir. Fak. Derg. 4 (1-2) : 7-13.

Ma G, Wang Y, Bao X, Hu Y, Liu Y, He L, Wang T, Meng F (2015) Nitrogen pollution characteristics and source analysis using the stable isotope tracing method in Ashi River, northeast China. Environ. Earth Sci. 73:4831-4839.

Ödemiş B, Sangün MK, Büyüktaş D (2007) Temporal Variations in Quantity and Quality of Orontes River, Turkey. Asian J. Chem. 19(1):711-723.

Özdilek HG, Sangün MK (2007) Monitoring Surface Water Quality of an International River (Asi River) During the 2006 Muslim Sacriface Holiday. Asian J. Chem. 19:701-705.

Padmalal D, Remya SI, Jyothi SJ, Baijulal B, Babu KN, Baiju RS (2012) Water quality and dissolved inorganic Fluxes of N. P. SO4 and K of a small catchment river in the Coast of India. Environ. Monit. Assess. 184:15411557.

Phung D, Huang C, Rutherford S, Dwirahmadi F, Chu C, Wang $X$, Nguyen $\mathrm{M}$, Nguyen $\mathrm{NH}$, DO CM, Nguyen $\mathrm{TH}$, Dinh TAD (2015)Temporal and spatial assessment of river surface water quality using multivariate statistical tachniques: atudy in Can Tho City. a Mekong Delta area. Vietnam. Environ. Monit. Assess. 187:229.

Prasanth SVS, Magesh NS, Jitheshlal KV, Chandrasekar N, Gangadhar K (2012) Evaluation of groundwater quality and its suitability for drinking and agricultural use in the coastal stretch of Alappuzha District, Kerala, India. Appl. Water Sci. 2:165-175.
Rather MI, Rashid I, Shahi N, Murtaza KO, Hassan K, Yousuf AR, Romshoo SA (2016) Massive land system changes impact water quality of the Jhelum River Kashmir Himalaya. Envir. Monit. Assess. 188:185.

Richards LA (1954) Diagnosis and improvement of saline and alkali soils. US Dep Agri. Handbook 60:147

Samarghandi MR, Nouri J, Mesdaghinia AR, Mahvi AH, Nasseri S, Vaezi F (2007)Efficiency removal of phenol. lead and cadmium by means of UV/TiO2/H2O2 processes. Int. J. Environ. Sci. Tech. 4(1):19-25.

Singh $P$, Chaturvedi RK, Mishra A, Kumari L, Singh R, Pal DB, Giri DD, Singh NL, Tiwary D, Mishra PK (2015) Assessment of ground and surface water quality along river Varuna. Varanasi. India. Environ. Monit. Assess. 187:170.

Singh KP, Basant N, Gupta S (2011) Support vector machines in water quality Management. Anal. Chim. Acta, 703:152-162.

WHO (1997) Guidelines for drinking-water quality, vol 1. WHO, Geneva

Yu YJ, Guan J, Ma YW, Yu SX, Guo HC, Bao LY (2010) Aquatic environmental quality variation in Lake Dianchi watershed. Procedia. Environ. Sci. 2:76-81.

Zeeshan M, Azeez PA (2016) Hydro-chemical characterization and quality assessment of a Western Himalayan river, Munawar Tawi, flowing through Rajouri district, Jammu and Kasmir, India. Environ. Monit. Assess. 188:520.

Zhang Y, Sillanpää M, Li C, Guo J, Qu B, Kang S (2015). River water quality across the Himalayan regions: elemental concentrations in headwaters of Yarlung Tsangbo, Indus and Ganges River. Environ. Earth Sci. 73: 4151-4163. 